durante o ano de 2002, a qual oscilou de acordo com a região do Brasil, sendo mais alta no sul (71\%) e consideravelmente mais baixa no nordeste $(24 \%)$ e, ainda, que as mulheres com maior nível de escolaridade tinham maior acesso a insumos e ações (64\% das mulheres com instrução superior ao primeiro grau) que as mulheres menos escolarizadas (19\% das mulheres sem instrução) também corroboram a necessidade de aprimorar a atenção ao prénatal, ao qual devem ser inquestionavelmente acrescidas todas as medidas para a redução da transmissão vertical do HIV assim como da sífilis congênita.

Heloísa Helena Marques
Referências

I. Ammann AJ. Is there an acquired immune deficiency syndrome in infants and children? Pediatr 1983, 72: 430-2.

2. Connor EM, Sperling RS, Gelber R, Kiselev P, Scott G, O'Sullivan MJ, VanDyke R, Bey M, Shearer W, Jacobson RL, et al. Reduction of maternal-infant transmission of human immunodeficiency virus type I with zidovudine treatment. Pediatric AIDS Clinical Trials Group Protocol 076 Study Group. N Engl J Med 1994; 331 : | |73-80.

3. Brasil. Ministério da Saúde. Secretaria de Vigilância em Saúde. Programa Nacional de DST/Aids. Projeto Nascer- Maternidades.

htpp://aids.gov.br/final/tratameto portaria2 I 042 I nov02 projetonascer.doc 4. Souza Junior PR, Szwarcwald CL, Barbosa Junior A, Carvalho MF, Castilho EA. Infecção pelo HIV durante a gestação: Estudo-Sentinela Parturiente, Brasil, 2002. Rev Saude Publica. 2004, 38:764-72. Epub $2004 \mathrm{Dec} 10$

\section{VACINAÇÃO ANTIPNEUMOCÓCICA EM CRIANÇAS COM DIABETES MELLITUS TIPO 1}

A vacinação antipneumocócica não faz parte do calendário oficial orientado pelo Ministério da Saúde do Brasil. Desde a década de 80, ela já é indicada para pacientes em situações especiais, por exemplo, diabéticos, por ser considerada uma importante intervenção para redução da morbi-mortalidade desses indivíduos'.

A orientação, recentemente divulgada pela Sociedade Brasileira de Pediatria, de inclusão da vacinação antipneumocócica para crianças até dois anos de idade no calendário vacinal provoca algumas reflexões ${ }^{2}$.

Investimentos têm sido feitos nos últimos anos para a produção de vacinas mais eficazes. Conforme dados publicados em 2003, a identificação das cepas de pneumococo causadoras de doença nas crianças brasileiras demonstra a possibilidade de proteção com o uso dessas vacinas $s^{3,4}$ e sua recomendação ${ }^{5}$.

As infecções pneumocócicas constituem importante causa de morbi-mortalidade em crianças, pessoas idosas ou portadoras de alguma condição clínica de base. A resistência bacteriana à penicilina, encontrada em algumas regiões, é um problema adicional a ser considerado 6 .

Em países desenvolvidos como os EUA, estima-se a ocorrência de 15-30 casos/100.000 pessoas/ano de bacteremia pneumocócica na população em geral, e 160 casos/l 00.000 em crianças. Pneumonia é a principal causa isolada de morte infantil; pneumonia pneumocócica é a causa mais comum de pneumonia adquirida na comunidade, tanto nos países em desenvolvimento quanto nos desenvolvidos. O S. pneumoniae é responsável por $25 \%$ a $35 \%$ dos casos de pneumonia que requerem hospitalização dos cerca de 500.000 que ocorrem anualmente nos EUA?

As infecções pneumocócicas causam, em média, 40.000 mortes/ano nos EUA, sendo que aproximadamente $50 \%$ delas seriam potencialmente evitadas pelo uso da vacina. Este índice de letalidade é maior que o de qualquer outra doença bacteriana prevenível por vacinação ${ }^{7}$.

No Brasil, a meningite pneumocócica é a segunda mais freqüente na infância, podendo levar a alto índice de seqüelas, com mortalidade de até $27,5 \%$. A alta incidência dessas infecções na população infantil aliada à gravidade potencial das mesmas certamente justifica a prevenção ${ }^{8}$.

No entanto, a diversidade de sorotipos dos pneumococos dificulta a produção de uma vacina eficaz. A vacina 23 -valente, que contém cerca de $85 \%$ a $90 \%$ dos sorotipos causadores de doença invasiva nos EUA, não oferece proteção para crianças abaixo de dois anos, devido às características da resposta imune ${ }^{7}$. A vacina conjugada heptavalente (PCV7), desenvolvida a partir dos principais sorotipos responsáveis por infecções invasivas nas crianças abaixo de seis anos, mostrou-se quase 100\% eficaz contra a doença pneumocócica invasiva ou resistência microbiana nos EUA? . Proteção semelhante não foi relatada no hemisfério Sul devido aos diferentes sorotipos.

No Brasil, considerando os sorotipos prevalentes em crianças até cinco anos, pressupõe-se cobertura para doença invasiva em torno de 52\%, podendo chegar a 
$70 \%$ em crianças até dois anos, para pneumonia, com o uso da PCV76.

A partir de 2000, a Academia Americana de Pediatria (AAP) recomenda a vacinação universal de crianças abaixo de dois anos, empregando-se a PCV- $7^{10}$. Segundo a AAP devem ainda receber a vacina crianças com idade entre 24 e 59 meses, portadoras de: drepanocitose ou outra hemoglobinopatia; asplenia ou disfunção esplênica; infecção pelo HIV; imunodeficiências e uso de terapia imunossupressora; insuficiência renal crônica, síndrome nefrótica, cardiopatias, pneumopatias, derivações liquóricas e diabetes mellitus. A associação com a vacina 23-valente melhoraria a cobertura nesses casos.

No Brasil não há, até o momento, dados sobre a prevalência das infecções pneumocócicas especificamente em crianças diabéticas. É atribuído um risco maior de infecções aos pacientes diabéticos devido a prováveis mecanismos genéticos e metabólicos anormais e distúrbios na resposta imune. Outros determinantes em crianças e adolescentes seriam as comorbidades episódios de descontrole glicêmico e acidose e episódios prévios de hospitalização que constituem fator de risco para infecção subseqüente grave por pneumococos.

Além disso, a complicação aguda mais grave e com maior taxa de mortalidade do paciente com diabetes tipo I, a cetoacidose diabética (CAD), é freqüentemente precipitada, nas crianças e adolescentes, por situação de estresse agudo, especialmente infeccioso. Sendo o S. pneumoniae o principal agente bacteriano de infecções respiratórias e meningites nesta faixa etária, a vacinação antipneumocócica teria, então, "dupla indicação": diminuição da morbi-mortalidade por esse agente e diminuição da incidência de CAD nestes pacientes, proporcionando ganhos não só de ordem humana e social como econômica.

Por outro lado, não foram demonstradas diferenças de resposta à vacina antipneumocócica (produção de anticorpos) em pacientes diabéticos em relação aos não diabéticos 1 .

É consenso que os pacientes diabéticos se beneficiam dessa vacinação. No entanto, apesar das recomendações do Centro de Controle de Doenças (CDC) dos EUA para vacinação antipneumocócica de todos os pacientes diabéticos, os resultados não têm sido os esperados. Em 1997, uma pesquisa mostrou que nenhum dos estados americanos tinha alcançado a meta de pelo menos $60 \%$ de índice vacinal contra pneumococos entre os diabéticos. As taxas de cobertura variavam de $22 \%$ a $48,6 \%^{12}$.
No Brasil, a vacinação antipneumocócica de crianças com anemia falciforme e fibrose cística, por exemplo, é indicada em alguns serviços especializados. O custo é, ainda, relativamente alto, mas a vacina está disponível nos Centros de Referência para Imunobiológicos Especiais do Programa Nacional de Imunizações, em todas as unidades da Federação. Apesar da recomendação já existente para a vacinação das crianças diabéticas esta conduta não tem sido seguida na prática diária.

O DMI incide principalmente em escolares e na puberdade, mas as crianças mais jovens são especialmente instáveis e de difícil controle. Nosso objetivo, ao comentar esses aspectos, é alertar para a utilidade de seguir essa recomendação e tornar a vacinação antipneumocócica mais um item do arsenal terapêutico para crianças e adolescentes diabéticos, mesmo considerando a atual composição das vacinas disponíveis, que não é a ideal para o Brasil.

\section{Ivani Novato Silva Paula Limp Borges Antônio José das Chagas Belo Horizonte - MG}

Referências

I.Valdez R, Narayan KMV, Geiss LS, Engelgau MM. The impact of diabetes mellitus on mortality associated with pneumonia and influenza among non-hispanic black and white US adults. A M J Public Health I999; 89: $|7| 5-2 \mid$

2.Calendário vacinal: www.sbp.com.br/img/documentos/doc_calendario2003.pdf

3.Nascimento-Carvalho CM, Freitas-Souza LS, Moreno-Carvalho AO, Alves NN, Caldas RM, Barberino MG e col. Cepas invasivas de pneumococo isoladas de crianças e adolescentes em Salvador. J Pediatr (Rio J) 2003;79:209- | 4 .

4.Lucarevschi BR, Baldacci ER, Bricks LF, Bertoli Cl, Teixeira LM, Mendes CMF e col. Colonização de orofaringe por S. pneumoniae em crianças de creches municipais de Taubaté-SP: correlação entre os principais sorotipos e a vacina pneumocócica conjugada heptavalente. J Pediatr (Rio J) 2003;79:21 5-20.

5.OselkaG.Prevenção da doença pneumocócica no Brasil.J Pediatr (Rio J) 2003;79: 195-6.

6.Brandileone MCC, Andrade ALS, DiFabio JL, Guerra LLS, Austrian R. Appropriateness of a pneumococcal conjugate vaccine in Brazil: potential impact of age and clinical diagnosis, with emphasis on meningitis. J Infect Dis 2003: 187: 1206-12.

7.Prevention of Pneumococcal Disease: recommendations of the Advisory Committee on Immunization Practices (ACIP). MMWR Morb Mortal Wkly Rep 1997; 46(RR-8): I-48.

8.Giebink GS. The prevention of pneumococcal disease in children. $N$ Engl J Med 2001; 345( | 6): I | 77-83.

9.Black S, Shinefield H, Fireman B, Lewis E, Ray P, Hansen JR, et al. Efficacy, safety and immunogenicity of heptavalent pneumococcal conjugate vaccine in children. Pediatr Infect Dis J 2000; 19: I 87-95.

10.Preventing Pneumococcal Disease Among Infants and Young Children: recommendations of the Advisory Committee on Immunization Practices (ACIP). MMWR Morb Mortal Wkly Rep 2000; 49 (RR-9): I - 28. I I.Smith AS, Poland GA: Use of influenza and pneumococcal vaccines in people with diabetes. Diabetes Care 23:95 - I08, 2000.

12.CDC. Influenza and pneumococcal vaccination rates among persons with Diabetes Mellitus - United States, I 997. JAMA 2000 283:48-50. 